Federal Reserve Bank of Minneapolis

\title{
Quarterly Review
}

Money (p. 3)

James Madison

The Debasement Puzzle:

An Essay on Medieval

Monetary History (p. 8)

Arthur J. Rolnick

François R. Velde

Warren E. Weber 


\title{
Quarterly Review vo. 21, No. 4
}

\author{
ISSN 0271-5287
}

This publication primarily presents economic research aimed at improving policymaking by the Federal Reserve System and other governmental authorities.

Any views expressed herein are those of the authors and not necessarily those of the Federal Reserve Bank of Minneapolis or the Federal Reserve System.

\author{
Editor: Arthur J. Rolnick \\ Associate Editors: Edward J. Green, Preston J. Miller, \\ Warren E. Weber \\ Economic Advisory Board: Lee E. Ohanian, Neil Wallace \\ Managing Editor: Kathleen S. Rolfe \\ Article Editors: Kathleen S. Rolfe, Jenni C. Schoppers \\ Designer: Phil Swenson \\ Typesetters: Mary E. Anomalay, Jody Decker \\ Technical Assistant: Shawn Hewitt \\ Circulation Assistant: Elaine R. Reed
}

The Quarterly Review is published by the Research Department of the Federal Reserve Bank of Minneapolis. Subscriptions are available free of charge.

Quarterly Review articles that are reprints or revisions of papers published elsewhere may not be reprinted without the written permission of the original publisher. All other Quarterly Review articles may be reprinted without charge. If you reprint an article, please fully credit the source - the Minneapolis Federal Reserve Bank as well as the Quarterly Review - and include with the reprint a version of the standard Federal Reserve disclaimer (italicized above). Also, please send one copy of any publication that includes a reprint to the Minneapolis Fed Research Department.

A list of past Quarterly Review articles and electronic files of many of them are available through the Minneapolis Fed's home page on the World Wide Web: http://woodrow.mpls.frb.fed.us.
Comments and questions about the Quarterly Review may be sent to

Quarterly Review

Research Department

Federal Reserve Bank of Minneapolis P.O. Box 291

Minneapolis, Minnesota 55480-0291

(Phone 612-204-6455 / Fax 612-204-5515).

Subscription requests may also be sent to the circulation assistant at err@res.mpls.frb.fed.us; editorial comments and questions, to the managing editor at ksr@res.mpls.frb.fed.us. 


\title{
Money*
}

\author{
James Madison
}

U.S. President, 1809-17

\section{Observations written ${ }^{1}$ posterior to the circular Address of Congress in Sept. 1779, and prior to their Act of March, $17800^{2}$}

It has been taken for an axiom in all our reasonings on the subject of finance, that supposing the quantity and demand of things vendible in a country to remain the same, their price will vary according to the variation in the quantity of the circulating medium; in other words, that the value of money will be regulated by its quantity. I shall submit to the judgment of the public some considerations which determine mine to reject the proposition as founded in error. Should they be deemed not absolutely conclusive, they seem at least to shew that it is liable to too many exceptions and restrictions to be taken for granted as a fundamental truth.

If the circulating medium be of universal value as specie, a local increase or decrease of its quantity, will not, whilst a communication subsists with other countries, produce a correspondent rise or fall in its value. The reason is obvious. When a redundancy of universal money prevails in any one country, the holders of it know their interest too well to waste it in extravagant prices, when it would be worth so much more to them elsewhere. When a deficiency happens, those who hold commodities, rather than part with them at an undervalue in one country, would carry them to another. The variation of prices in these cases, cannot therefore exceed the expence and insurance of transportation.
*This essay originally appeared in two parts, in the December 19 and 22, 1791, issues of Philip Freneau's National Gazette of Philadelphia. The version printed here is the edited and annotated version from The Papers of James Madison, vol. 1, 16 March 1751-16 December 1779, ed. William T. Hutchinson and William M. E. Rachal (Chicago: University of Chicago Press, 1962), pp. 302-10. The note referenced by a dagger $(\dagger)$ is James Madison's; the numbered notes are those of the University of Chicago Press editors. This version of the essay is reprinted with the permission of the University of Chicago Press. (1) 1962 by The University of Chicago. All rights reserved.

IThe original manuscript of the essay is not known to be extant. In the Tracy W. McGregor Library, University of Virginia, is a transcript of about the first one-third of the article, which John C. Payne probably copied from the newspaper version of it.

${ }^{2}$ Pledging on September 1, 1779, not to increase its $\$ 160$ million of outstanding bills of credit by more than 25 percent, and that only in case of a dire emergency, the Continental Congress had John Jay draft a "Circular Address" to the states (adopted September 13) exhorting them to supply enough soldiers, money, and matériel to restore public credit and advance the common cause. And yet, by March 18, 1780, the gloomy situation obliged Congress to authorize the states to issue new bills of credit and declare that the old continental issues would be redeemed at only one-fortieth of their face value (Journals of the Continental Congress, XV, 1052-62; XVI, 262-67). Although in the prefatory note Madison declared that he wrote his essay during the six months intervening between these two actions by Congress, he probably could have narrowed the time to the period from late in December 1779 to early in March of the next year.

In his brief third-person autobiography, written long afterward, Madison mentioned his election to Congress on December 14, 1779, and then added that "To prepare himself for this service, he employed an unavoidable detention from it in making himself acquainted with the state of Continental affairs, and particularly that of the finances which, owing to the depreciation of the paper currency, was truly deplorable. The view he was led to take of the evil, and its causes, was put on paper, now to be found in several periodical publications, particularly Freneau's National Gazette." By "unavoidable detention" he most likely referred to his necessary preparations at Montpelier for his residence in Philadelphia and the heavy snow which delayed his departure for that city until March 6, 1780, or for some days after he had planned to begin the trip. The essay was printed as the fourth in Madison's series of seventeen politically tinged articles appearing in Freneau's newspaper late in President Washington's first term. Even though Madison may have revised his original manuscript before releasing it for publication, it deals with a problem which was much less acute by 1791 than when he wrote the essay nearly twelve years earlier. 
Suppose a country totally unconnected with Europe, or with any other country, to possess specie in the same proportion to circulating property that Europe does; prices there would correspond with those in Europe. Suppose that so much specie were thrown into circulation as to make the quantity exceed the proportion of Europe tenfold, without any change in commodities, or in the demand for them: as soon as such an augmentation had produced its effect, prices would rise tenfold; or which is the same thing, money would be depreciated tenfold. In this state of things, suppose again, that a free and ready communication were opened between this country and Europe, and that the inhabitants of the former, were made sensible of the value of their money in the latter; would not its value among themselves immediately cease to be regulated by its quantity, and assimilate itself to the foreign value?

Mr. Hume in his discourse on the balance of trade supposes, "that if four fifths of all the money in Britain were annihilated in one night, and the nation reduced to the same condition, in this particular, as in the reigns of the Harrys and Edwards, that the price of all labour and commodities would sink in proportion, and every thing be sold as cheap as in those ages: That, again, if all the money in Britain were multiplied fivefold in one night, a contrary effect would follow." This very ingenious writer seems not to have considered that in the reigns of the Harrys and Edwards, the state of prices in the circumjacent nations corresponded with that of Britain; whereas in both of his suppositions, it would be no less than four fifths different. Imagine that such a difference really existed, and remark the consequence. Trade is at present carried on between Britain and the rest of Europe, at a profit of 15 or 20 per cent. Were that profit raised to 400 per cent. would not their home market, in case of such a fall of prices, be so exhausted by exportation - and in case of such a rise of prices, be so overstocked with foreign commodities, as immediately to restore the general equilibrium? Now, to borrow the language of the same author, "the same causes which would redress the inequality were it to happen, must forever prevent it, without some violent external operation." 3

The situation of a country connected by commercial intercourse with other countries, may be compared to a single town or province whose intercourse with other towns and provinces results from political connection. Will it be pretended that if the national currency were to be accumulated in a single town or province, so as to exceed its due proportion five or tenfold, a correspondent depreciation would ensue, and every thing be sold five or ten times as dear as in a neighboring town or province?

If the circulating medium be a municipal one, as paper currency, still its value does not depend on its quantity. It depends on the credit of the state issuing it, and on the time of its redemption; and is no otherwise affected by the quantity, than as the quantity may be supposed to endanger or postpone the redemption.

That it depends in part on the credit of the issuer, no one will deny. If the credit of the issuer, therefore be perfectly unsuspected, the time of redemption alone will regulate its value.

To support what is here advanced, it is sufficient to appeal to the nature of paper money. It consists of bills or notes of obligation payable in specie to the bearer, either on demand or at a future day. Of the first kind is the paper currency of Britain, and hence its equivalence to specie. Of the latter kind is the paper currency of the United States, and hence its inferiority to specie. But if its being redeemable not on demand but at a future day, be the cause of its inferiority, the distance of that day, and not its quantity, ought to be the measure of that inferiority.

It has been shewn that the value of specie does not fluctuate according to local fluctuations in its quantity. Great Britain, in which there is such an immensity of circulating paper, shews that the value of paper depends as little on its quantity as that of specie, when the paper represents specie payable on demand. Let us suppose that the circulating notes of Great Britain, instead of being payable on demand, were to be redeemed at a future day, at the end of one year for example, and that no interest was due on them. If the same assurance prevailed that at the end of the year they would be equivalent to specie, as now prevails that they are every moment equivalent, would any other effect result from such a change, except that the notes would suffer a depreciation equal to one year's interest? They would in that case represent, not the nominal sum expressed on the face of them, but the sum remaining after a deduction of one year's interest. But if when they represent the full nominal sum of specie, their circulation contributes no more to depreciate them, than the circulation of the specie itself would do; does it not follow, that if they represented a sum of specie less than the nominal inscription, their circulation ought to depreciate them no

\footnotetext{
${ }^{3}$ Madison accurately reflects the thought, but does not always quote the exact words, of David Hume in his Political Discourses (Edinburgh, 1752), pp. 82-83.
} 
more than so much specie, if substituted, would depreciate itself? We may extend the time from one, to five, or to twenty years; but we shall find no other rule of depreciation than the loss of the intermediate interest.

What has been here supposed with respect to Great Britain has actually taken place in the United States. Being engaged in a necessary war without specie to defray the expence, or to support paper emissions for that purpose redeemable on demand, and being at the same time unable to borrow, no resource was left, but to emit bills of credit to be redeemed in future. The inferiority of these bills to specie was therefore incident to the very nature of them. If they had been exchangeable on demand for specie, they would have been equivalent to it; as they were not exchangeable on demand, they were inferior to it. The degree of their inferiority must consequently be estimated by the time of their becoming exchangeable for specie, that is the time of their redemption.

To make it still more palpable that the value of our currency does not depend on its quantity, let us put the case, that Congress had, during the first year of the war, emitted five millions of dollars to be redeemed at the end of ten years; that, during the second year of the war, they had emitted ten millions more, but with due security that the whole fifteen millions should be redeemed in five years; that, during the two succeeding years, they had augmented the emissions to one hundred millions, but from the discovery of some extraordinary sources of wealth, had been able to engage for the redemption of the whole sum in one year: it is asked, whether the depreciation, under these circumstances, would have increased as the quantity of money increased - or whether on the contrary, the money would not have risen in value, at every accession to its quantity $?^{4}$

It has indeed happened, that a progressive depreciation of our currency has accompanied its growing quantity; and to this is probably owing in a great measure the prevalence of the doctrine here opposed. When the fact however is explained, it will be found to coincide perfectly with what has been said. Every one must have taken notice that, in the emissions of Congress, no precise time has been stipulated for their redemption, nor any specific provision made for that purpose. A general promise entitling the bearer to so many dollars of metal as the paper bills express, has been the only basis of their credit. Every one therefore has been left to his own conjectures as to the time the redemption would be fulfilled; and as every addition made to the quantity in circulation, would naturally be supposed to remove to a proportionally greater distance the redemption of the whole mass, it could not happen otherwise than that every additional emission would be followed by a further depreciation.

In like manner has the effect of a distrust of public credit, the other source of depreciation, been erroneously imputed to the quantity of money. The circumstances under which our early emissions were made, could not but strongly concur, with the futurity of their redemption, to debase their value. The situation of the United States resembled that of an individual engaged in an expensive undertaking, carried on, for want of cash, with bonds and notes secured on an estate to which his title was disputed; and who had besides, a combination of enemies employing every artifice to disparage that security. A train of sinister events during the early stages of the war likewise contributed to increase the distrust of the public ability to fulfill their engagements. Before the depreciation arising from this cause was removed by the success of our arms, and our alliance with France, it had drawn so large a quantity into circulation, that the quantity itself soon after begat a distrust of the public disposition to fulfill their engagements; as well as new doubts, in timid minds, concerning the issue of the contest. From that period, this cause of depreciation has been incessantly operating. It has first conduced to swell the amount of necessary emissions, and from that very amount has derived new force and efficacy to itself. Thus, a further discredit of our money has necessarily followed the augmentation of its quantity; but every one must perceive, that it has not been the effect of the quantity, considered in itself, but considered as an omen of public bankruptcy. $\dagger^{5}$

\footnotetext{
${ }^{4}$ The portion of the essay in the issue of the National Gazette for December 19 , 1791, ends here. The remainder is in the issue of December 22, 1791.

$\dagger$ As the depreciation of our money has been ascribed to a wrong cause, so, it may be remarked, have effects been ascribed to the depreciation, which result from other causes. Money is the instrument by which men's wants are supplied, and many who possess it will part with it for that purpose, who would not gratify themselves at the expence of their visible property. Many also may acquire it, who have no visible property. By increasing the quantity of money therefore, you both increase the means of spending, and stimulate the desire to spend; and if the objects desired do not increase in proportion, their price must rise from the influence of the greater demand for them. Should the objects in demand happen, at the same juncture, as in the United States, to become scarcer, their prices must rise in a double proportion.

It is by this influence of an augmentation of money on demand, that we ought to account for that proportional level of money, in all countries, which Mr. Hume attributes to its direct influence on prices. When an augmentation of the national coin takes place, it may be supposed either, 1. not to augment demand at all; or, 2. to augment it so gradually that a proportional increase of industry will supply the objects of it; or, 3 . to augment it so rapidly that the domestic market may prove inadequate, whilst the taste for distinction natural to wealth, inspires, at the same time, a preference for for-
} 
Whether the money of a country, then, be gold and silver, or paper currency, it appears that its value is not regulated by its quantity. If it be the former, its value depends on the general proportion of gold and silver, to circulating property throughout all countries having free inter communication. If the latter, it depend[s] on the credit of the state issuing it, and the time at which it is to become equal to gold and silver.

Every circumstance which has been found to accelerate the depreciation of our currency naturally resolves itself into these general principles. The spirit of monopoly hath affected it in no other way than by creating an artificial scarcity of commodities wanted for public use, the consequence of which has been an increase of their price, and of the necessary emissions. Now it is this increase of emissions which has been shewn to lengthen the supposed period of their redemption, and to foster suspicions of public credit. Monopolies destroy the natural relation between money and commodities; but it is by raising the value of the latter, not by debasing that of the former. Had our money been gold or silver, the same prevalence of monopoly would have had the same effect on prices and expenditures; but these would not have had the same effect on the value of money.

The depreciation of our money has been charged on misconduct in the purchasing departments: but this misconduct must have operated in the same manner as the spirit of monopoly. By unnecessarily raising the price of articles required for public use, it has swelled the amount of necessary emissions, on which has depended the general opinion concerning the time and the probability of their redemption.

The same remark may be applied to the deficiency of imported commodities. The deficiency of these commodities has raised the price of them; the rise of their price has increased the emissions for purchasing them; and with the increase of emissions, have increased suspicions concerning their redemption.

Those who consider the quantity of money as the criterion of its value, compute the intrinsic depreciation of our currency by dividing the whole mass by the supposed necessary medium of circulation. Thus supposing the medium necessary for the United States to be $30,000,000$ dollars, and the circulating emissions to be $200,000,000$ the intrinsic difference between paper and specie will be nearly as 7 for 1 . If its value depends on the time of its redemption, as hath been above maintained, the real difference will be found to be considerably less. Suppose the period neces- sary for its redemption to be 18 years, as seems to be understood by Congress; 100 dollars of paper 18 years hence will be equal in value to 100 dollars of specie; for at the end of that term, 100 dollars of specie may be demanded for them. They must consequently at this time be equal to as much specie as, with compound interest, will amount, in that number of years, to 100 dollars. If the interest of money be rated at 5 per cent. this present sum of specie will be about 41 1-2 dollars. Admit, however the use of money to be worth 6 per cent. about 35 dollars will then amount in 18 years to 100.35 dollars of specie therefore is at this time equal to 100 of paper; that is, the man who would exchange his specie for paper at this discount, and lock it in his desk for 18 years, would get 6 per cent. for his money. The proportion of 100 to 35 is less than 3 to 1 . The intrinsic depreciation of our money therefore, according to this rule of computation, is less than 3 to 1 ; instead of 7 to 1 , according to the rule espoused in the circular address, ${ }^{6}$ or 30 or 40 to 1 , according to its currency in the market.

I shall conclude with observing, that if the preceding principles and reasoning be just, the plan on which our domestic loans have been obtained, must have operated in a manner directly contrary to what was intended. A loanoffice certificate differs in nothing from a common bill of credit, except in its higher denomination, and in the interest

eign luxuries. The first case can seldom happen. Were it to happen, no change in prices, nor any efflux of money, would ensue; unless indeed, it should be employed or loaned abroad. The superfluous portion would be either hoarded or turned into plate. The second case can occur only where the augmentation of money advances with a very slow and equable pace; and would be attended neither with a rise of prices, nor with a superfluity of money. The third is the only case, in which the plenty of money would occasion it to overflow into other countries. The insufficiency of the home market to satisfy the demand would be supplied from such countries as might afford the articles in demand; and the money would thus be drained off, till that and the demand excited by it, should fall to a proper level, and a balance be thereby restored between exports and imports.

The principle on which Mr. Hume's theory, and that of Montesquieu's before him, is founded, is manifestly erroneous. He considers the money in every country as the representative of the whole circulating property and industry in the country; and thence concludes, that every variation in its quantity must increase or lessen the portion which represents the same portion of property and labor. The error lies in supposing, that because money serves to measure the value of all things, it represents and is equal in value to all things. The circulating property in every country, according to its market rate, far exceeds the amount of its money. At Athens oxen, at Rome sheep, were once used as a measure of the value of other things. It will hardly be supposed, they were therefore equal in value to all other things.

${ }^{5}$ Madison's entire footnote is in italics in the National Gazette. In the last paragraph of the footnote, he refers to Book XXII of Montesquieu's De l'esprit des lois, first published in Geneva in 1748 and soon thereafter translated into English. Madison's daring in challenging the correctness of this redoubtable authority is noted by Paul Merrill Spurlin in his Montesquieu in America, 1760-1801 (Baton Rogue, La., 1940), pp. 175-76.

${ }^{6}$ See note 2. 
allowed on it; and the interest is allowed, merely as a compensation to the lender, for exchanging a number of small bills, which being easily transferable, are most convenient, for a single one so large as not to be transferable in ordinary transactions. As the certificates, however, do circulate in many of the more considerable transactions, it may justly be questioned, even on the supposition that the value of money depended on its quantity, whether the advantage to the public from the exchange, would justify the terms of it. But dismissing this consideration, I ask whether such loans do in any shape, lessen the public debt, and thereby render the discharge of it less suspected or less remote? Do they give any new assurance that a paper dollar will be one day equal to a silver dollar, or do they shorten the distance of that day? Far from it: The certificates constitute a part of the public debt no less than the bills of credit exchanged for them, and have an equal claim to redemption within the general period; nay, are to be paid off long before the expiration of that period, with bills of credit, which will thus return into the general mass, to be redeemed along with it. Were these bills, therefore, not to be taken out of circulation at all, by means of the certificates, not only the expence of offices for exchanging, re-exchanging, and annually paying the interest, would be avoided; but the whole sum of interest would be saved, which must make a formidable addition to the public emissions, protract the period of their redemption, and proportionally increase their depreciation. No expedient could perhaps have been devised more preposterous and unlucky. In order to relieve public credit sinking under the weight of an enormous debt, we invest new expenditures. In order to raise the value of our money, which depends on the time of its redemption, we have recourse to a measure which removes its redemption to a more distant day. Instead of paying off the capital to the public creditors, we give them an enormous interest to change the name of the bit of paper which expresses the sum due to them; and think it a piece of dexterity in finance, by emitting loan-office certificates, to elude the necessity of emitting bills of credit. 